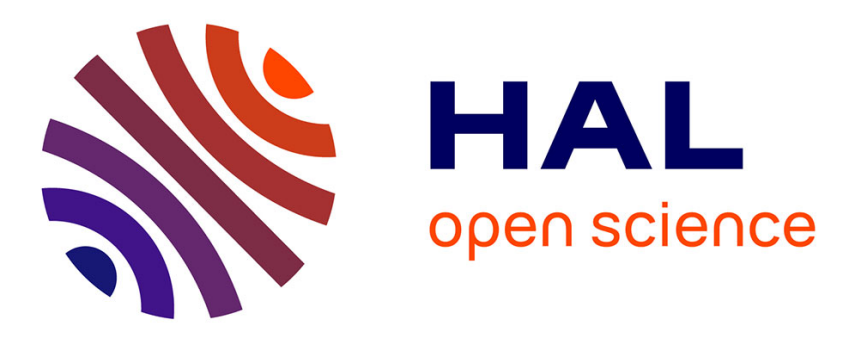

\title{
Inversion of dislocation loop nature driven by cluster migration in self-ion irradiated nickel
}

Kan Ma, Brigitte Décamps, Anna Fraczkiewicz, Frédéric Prima, Marie

Loyer-Prost

\section{- To cite this version:}

Kan Ma, Brigitte Décamps, Anna Fraczkiewicz, Frédéric Prima, Marie Loyer-Prost. Inversion of dislocation loop nature driven by cluster migration in self-ion irradiated nickel. Scripta Materialia, 2021, 208, pp.114338. 10.1016/j.scriptamat.2021.114338 * cea-03482273

\section{HAL Id: cea-03482273 \\ https://hal-cea.archives-ouvertes.fr/cea-03482273}

Submitted on 15 Dec 2021

HAL is a multi-disciplinary open access archive for the deposit and dissemination of scientific research documents, whether they are published or not. The documents may come from teaching and research institutions in France or abroad, or from public or private research centers.
L'archive ouverte pluridisciplinaire HAL, est destinée au dépôt et à la diffusion de documents scientifiques de niveau recherche, publiés ou non, émanant des établissements d'enseignement et de recherche français ou étrangers, des laboratoires publics ou privés. 


\section{Inversion of dislocation loop nature driven by cluster migration in self-ion irradiated nickel}

2 Kan MA ${ }^{\mathrm{a}, \mathrm{d}, 1}$, Brigitte DÉCAMPS ${ }^{\mathrm{b}}$, Anna FRACZKIEWICZ ${ }^{\mathrm{c}}$, Frédéric PRIMA ${ }^{\mathrm{d}}$ and Marie

3 LOYER-PROST ${ }^{\mathrm{a}^{*}}$.

4 anniversité Paris-Saclay, CEA, Service de Recherches de Métallurgie Physique, Gif-sur-Yvette,

5 France;

6 baboratoire de Physique des 2 infinis Irène Joliot-Curie (IJCLab), Université Paris-Saclay, Orsay,

7 France;

8 'MINES Saint-Etienne, Université de Lyon, CNRS, UMR 5307 LGF, Centre SMS, 42023, Saint-

9 Etienne, France;

10 dPSL Research University, Chimie ParisTech-CNRS, Institut de Recherche de Chimie Paris, Paris, 11 France.

$12{ }^{1}$ Currently at the School of Metallurgy and Materials, University of Birmingham B15 2TT, United

13 Kingdom.

14

$15 *$ Corresponding author: Marie LOYER-PROST.

16 Mail: marie.loyer-prost@cea.fr

17 Courrier: CEA Saclay, DES/ISAS/DMN/SRMP/JANNUS (Bât 126, pièce 58), PC. 162, 91191

18 Gif-sur-Yvette CEDEX, France.

19 Telephone +33(0)1 69082468 .

20 


\section{$1 \quad$ Abstract}

2

Nickel is widely used as fcc model material to obtain insight into fundamental mechanisms

3 of radiation damage. This work presents irradiation of high-purity nickel using self-ions at $450^{\circ} \mathrm{C}$

4 and fine analysis of dislocation loops in specimens prepared by Focus Ion Beam using

5 Transmission Electron Microscopy. For the first time to our knowledge, an inversion of loop

6 nature (vacancy-type in irradiated zones v.s. interstitial-type in unirradiated zones) and a change

7 of loop Burgers vector $(1 / 3<111>$ and $1 / 2<110>$ loops v.s. only $1 / 2<110>$ loops $)$ is identified

8 along the implantation direction in irradiated nickel. This change may be attributed to the

9 formation of interstitial $\langle 110\rangle$ crowdions and their long-range one-dimension migration. A

10 defect-free layer related to the annihilation of vacancy defects by injected atoms is detected. . It

11 allows the identification of the injection peak which is uncommon for self-ion irradiated

12 specimens and validates the damage calculations.

13

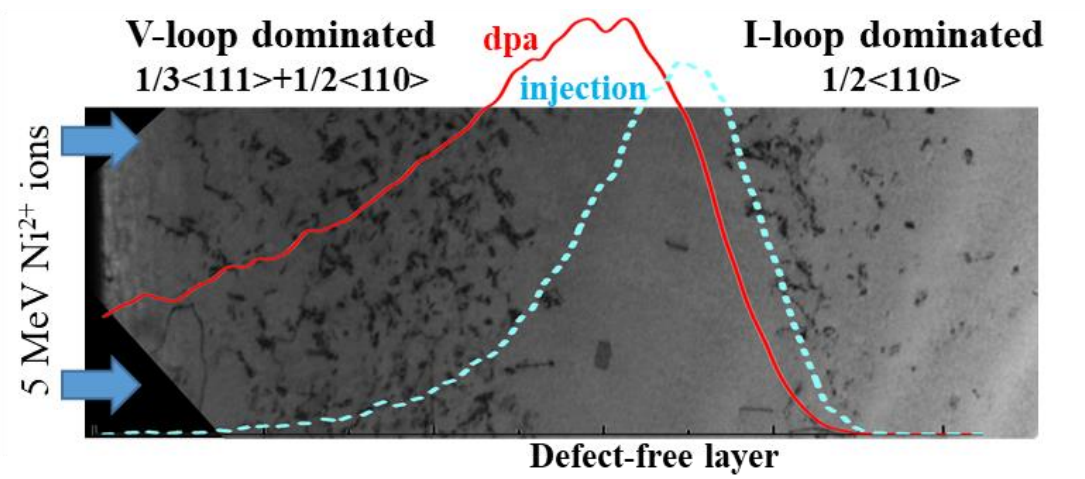

145 keywords

15 Nickel, microstructure, dislocation, TEM, radiation damage 
$1 \quad$ Novel austenitic materials [1,2] and single-phase concentrated solid-solution alloys 2 including high entropy alloys (HEA) [3,4] are new classes of face-cubic centered (fcc) metallic 3 materials. They display exceptional improvement of radiation-resistance compared to traditional 4 fcc materials thus are promising candidates for future nuclear applications [5,6]. However, their 5 reliability under irradiation requires further examinations and a better understanding of the 6 fundamental mechanisms of radiation damage in the fcc structures.

For this purpose, pure nickel $(\mathrm{Ni})$ and Ni-based alloys are widely used as fcc model 8 materials to investigate radiation-induced defects and solute effects [7-10]. The irradiation 9 behavior of $\mathrm{Ni}$ as a reference system draws particular attention. Radiation-induced dislocation 10 loops were detected as a characteristic defect in the early stage of irradiation in $\mathrm{Ni}[7,9,11,12]$. 11 Therefore, the loop formation and evolution were largely studied over a wide range of temperatures and doses in $\mathrm{Ni}[9,13-17]$. The same interstitial nature of loops was identified in most of experiments. The stability of interstitial loops and their growth mechanism under 14 irradiation were explained by the dislocation bias model in which dislocation lines/loops absorb 15 preferentially interstitial atoms $[13,14]$. Nevertheless, recently, vacancy-type loops were 16 identified for the first time as dominant in the microstructure, within the damage zones of $\mathrm{Ni}$ 17 irradiated by self-ions at $450^{\circ} \mathrm{C}$ [18]. The same vacancy nature was identified in as-irradiated TEM thin foils [19] and Focus Ion Beam (FIB) specimens up to $1.5 \mu$ m irradiation depth [18]. Interstitial Frank loops were only occasionally detected within vacancy-type Frank loops eradicating the outer vacancy loop [18]. These observations contrasts with the well-established 21 interstitial loop nature in literature and could be explained by the high mobility of interstitial clusters escaping from the damage production zone [9,19-21]. To better elucidate the mechanisms, 23 full characterization of dislocation loops (their nature and type) along the ion irradiation profile is therefore essential and has never been explored in ion-irradiated $\mathrm{Ni}$. In this work, ultra-high-purity nickel is manufactured by cold crucible induction melting at 26 the Ecole des Mines de Saint Etienne with measured impurities in mass ppm: $\mathrm{O}<2, \mathrm{C}<8, \mathrm{~N}<2$, $27 \mathrm{~S}<2.3 \mathrm{~mm}$ diameter foils are irradiated at the JANNuS-Saclay platform using a raster beam of 5 
$1 \mathrm{MeV} \mathrm{Ni}^{2+}$ ions at $450^{\circ} \mathrm{C}$ up to $2.3 \times 10^{15}$ ions. $\mathrm{cm}^{-2}$. Dislocation loops and their nature are

2 investigated from the surface up to $3 \mu \mathrm{m}$ depth. The radiation damage is calculated using the

3 Stopping and Range of Ions in Matter 2013 code (SRIM) [22] and IRADINA [23] in Kinchin-

4 Pease mode with a displacement threshold energy of $40 \mathrm{eV}$. Good agreement is obtained between

5 two codes and the damage profile by SRIM is shown in Fig. 1(a). The dose is about 0.7 dpa at the

6 surface and $2.2 \mathrm{dpa}$ at the damage peak. Cross-sectional samples are lifted-out using FIB equipped

7 on an FEI Helio 650 NanoLab dual-beam Scanning Electron Microscopy (SEM) followed by a

8 flash polishing technique [24] to remove FIB-induced damage. The irradiated microstructure in

9 FIB specimens is characterized with a $200 \mathrm{kV}$ FEI TECNAI G2 TEM. Conventional TEM

10 techniques are applied to characterize dislocation loops using invisibility criterion [25] and inside-

11 outside method [26-28] respectively for the determination of loop Burgers vectors and natures

12 under Finish-Start/Right-Hand convention [29].

13 Fig. 1(a) presents the typical panorama obtained for irradiated microstructures with the

14 damage and injection profiles. The damage and injection peaks are respectively at $1.5 \mu \mathrm{m}$ and 1.8

$15 \mu \mathrm{m}$ in depth. Dislocation loops are the main defect formed in the microstructure. Only two voids

16 are detected in the specimen and their density is neglected. Some small defects $(<5 \mathrm{~nm})$ are

17 detected. Some of them exhibit a triangle form so could be Staking Fault Tetrahedrons (SFT) (Fig.

18 S1 in supplementary materials). Generally, it is difficult to distinguish them from loop to SFT. In

19 this work, we will focus on the dislocation loops and lines as they are dominating the

20 microstructure. The average loop size, loop density and dislocation line density are measured and

21 plotted in Fig. 1(e). A strong heterogeneity of the defect distribution is thus revealed as observed

22 in Fig. 1(a). Similar phenomenon is observed in other samples with different orientations (Fig. S2

23 in supplementary materials). 


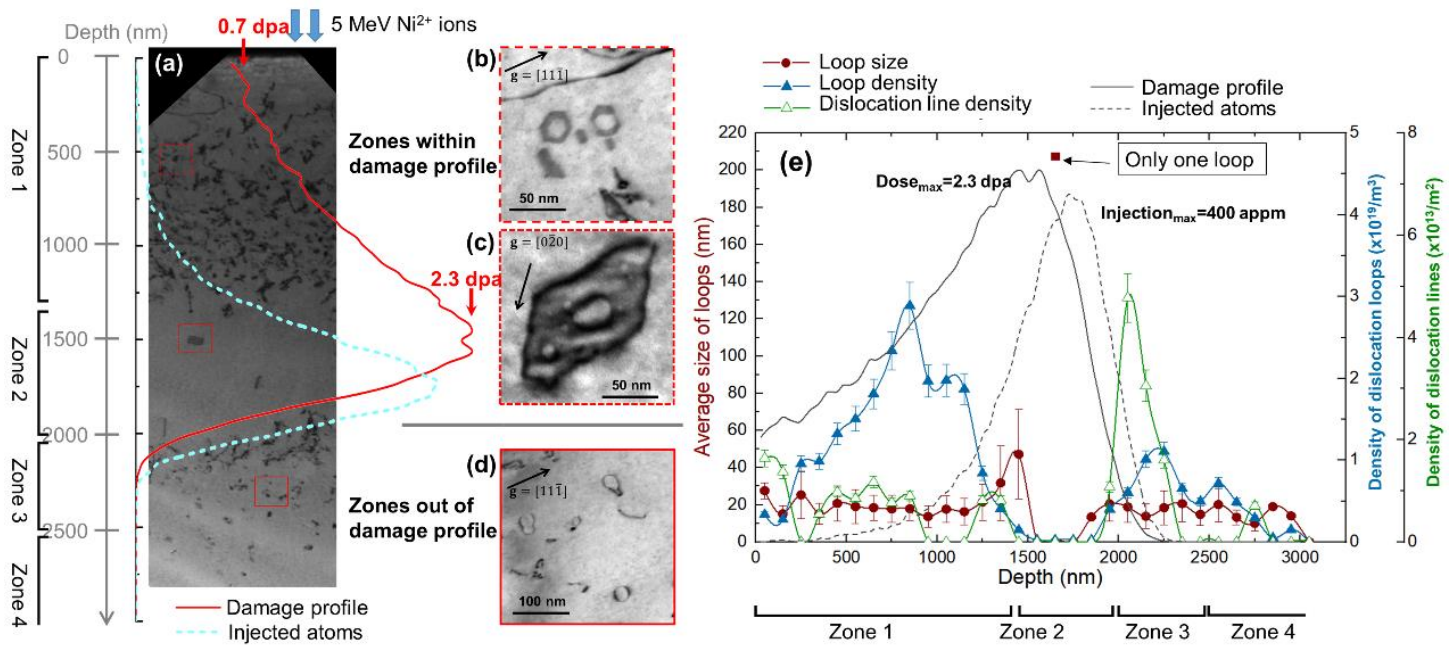

Fig. 1 Microstructure irradiated up to $2.3 \times 10^{15}$ ions.cm- ${ }^{2}$ at $450^{\circ} \mathrm{C}$ : (a) Low magnification BrightField (BF) TEM micrograph image showing the general microstructure with the damage profile and injected atoms calculated using SRIM-2013; (b-c) BF images of two typical Frank loops at depth $\leq 1.5 \mu \mathrm{m}$ with diffraction vectors $\mathrm{g}$ indicated by black arrows; (d) BF images of perfect loops outside the damage profile; (e) depth-dependency of the average size and density of loops as well as the density of dislocation lines.

The microstructure can be divided into four zones. The first damaged zone $(0-1.3 \mu \mathrm{m})$ is

9 within the damage profile with limited injected atoms. In this zone, both Frank loops and perfect

10 loops are detected. Fig. 1(b) shows some typical single-layer and double-layer Frank loops in this

11 zone. In fact, all single-layer Frank loops and the outer loops of double-layer ones are vacancy-

12 type and segmented as shown in Fig. 2. Multiple $\pm \mathrm{g}$ pairs are used and the same results are

13 obtained. 

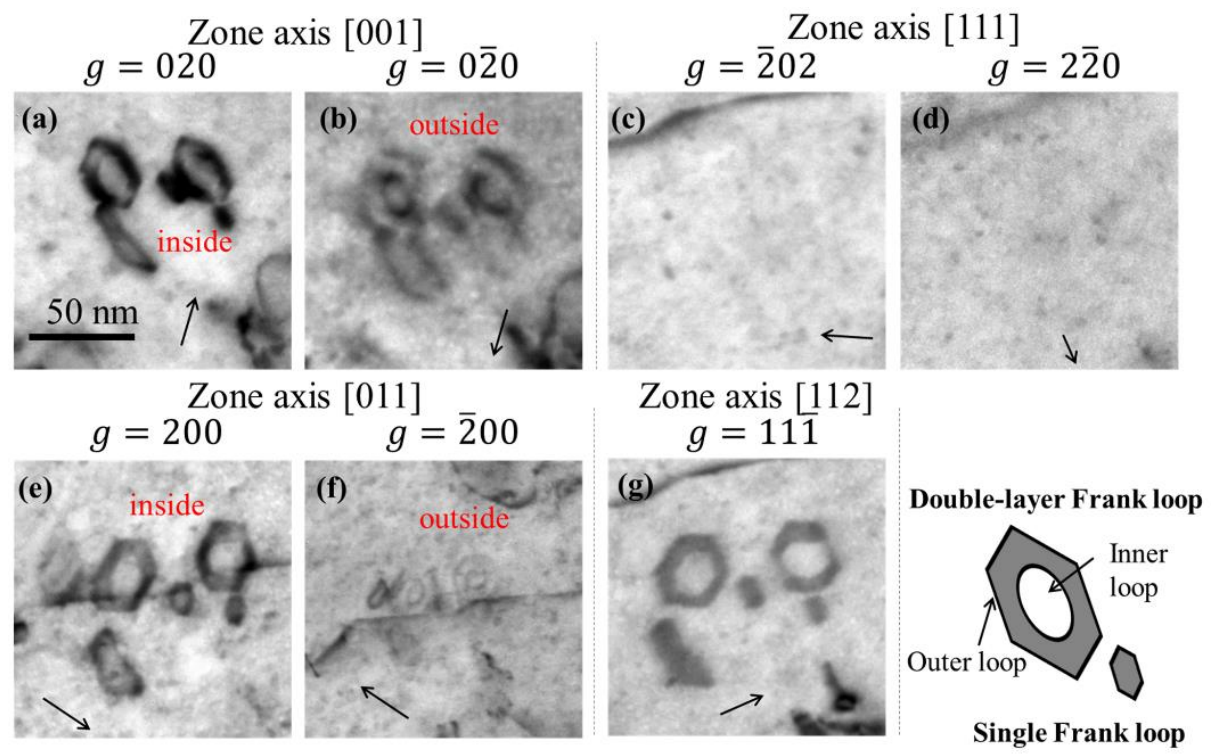

(h)

\begin{tabular}{lccccccc}
\hline \multirow{2}{*}{ Loops } & \multicolumn{2}{c}{ Contrast of loops (zone axis [001]) } & & \multirow{2}{*}{..b for $+\mathbf{g}$} & $\mathbf{b}$ & Nature \\
\cline { 2 - 6 } & $\mathbf{b}$ direction & $+\mathbf{g}=[020]$ & $-\mathbf{g}=[0 \overline{2} 0]$ & & & \\
\hline $\begin{array}{l}\text { Single loop } / \\
\text { Outer loop }\end{array}$ & {$[111]$} & inside & outside & $<0$ & {$[\overline{1} \overline{1} \overline{1}]$} & vacancy \\
\hline Inner loop & {$[111]$} & outside & inside & $>0$ & {$[111]$} & interstitial \\
\hline
\end{tabular}

(i)

\begin{tabular}{|c|c|c|c|c|c|c|}
\hline \multirow{2}{*}{ Loops } & \multicolumn{3}{|c|}{ Contrast of loops (zone axis [011]) } & \multirow{2}{*}{ g.b for $+\mathbf{g}$} & \multirow{2}{*}{ b } & \multirow{2}{*}{ Nature } \\
\hline & b direction & $+\mathbf{g}=[200]$ & $-\mathbf{g}=[\overline{2} 00]$ & & & \\
\hline $\begin{array}{l}\text { Single loop / } \\
\text { Outer loop }\end{array}$ & [111] & inside & outside & $<0$ & {$[\overline{1} \overline{1} \overline{1}]$} & vacancy \\
\hline Inner loop & [111] & outside & inside & $>0$ & [111] & interstitial \\
\hline
\end{tabular}

Fig. 2 Determination of the Burgers vectors of the Frank loops in thin foil Ni irradiated at $450^{\circ} \mathrm{C}$ within the damage profile: (a-g) Bright-field TEM images of the Frank loop under different twobeam conditions with diffraction vector $\mathbf{g}$ indicated by arrows with the same scale bar in (a); (h) and (i) tables of loop nature determination based on two $\pm \mathrm{g}$ pairs using the inside-outside method [27].

Fig. 2 displays the determination of both Burgers vector and nature of Frank loops. Their

8 Burgers vector is identified as $\pm_{0} / 3[111]$ (see Table S.1 in the supplementary material) as they

9 are invisible with $\mathrm{g}=[\overline{2} 02]$ and $\mathrm{g}=[2 \overline{2} 0](\mathbf{g} . \mathbf{b}=0)$. Their inside-outside behavior is summarized in

10 Fig. 2(f), leading to a Burgers vector of $\mathrm{a}_{0} / 3[\overline{1} \overline{1} \overline{1}]$. As the loop plan normal $\mathbf{n}$ and the Burgers

11 vector $\mathbf{b}$ are pointing in opposite directions, i.e. $\mathbf{n} . \mathbf{b}<0$, they are vacancy-type loops. The inner

12 loops are also Frank loops but interstitial-type, so they eradicate the stacking fault of the outer

13 loop, which was analyzed in details in [18]. Meanwhile, the same nature of perfect loops is also

14 observed within the zone. Fig. 3 presents the determination of loop nature for a typical perfect 
1 loop within the damage zone. The outer loop and inner loops are coplanar as they are almost 2 superposed in the edge-on position in Fig. 3(a). Their habit plane is thus close to (110), i.e. $3 \mathbf{n} \approx[110]$. From their visibility (Table S.1) and inside-outside behavior (for $\mathbf{g}= \pm[200]$ close to the 4 zone axis [011]), their Burgers vector is $a_{0}[\overline{1} \overline{1} 0]$, resulting in vacancy nature as $\mathbf{n} . \mathbf{b}<0$. Besides, 5 they are close to edge position. Overall, only vacancy loops are detected in the first damage zone. 6 The second zone $(1.3-2.0 \mu \mathrm{m})$ is the overlap of the damage and injection profile. This layer is 7 almost defect-free: only one vacancy-type Frank large loop is detected as shown in Fig. 1(c).
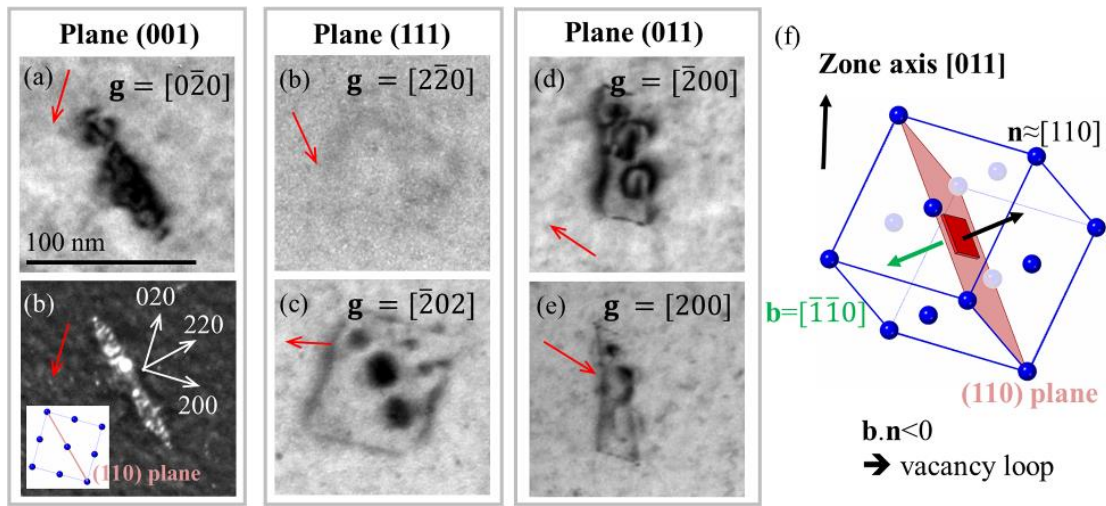

Fig. 3 Determination of the Burgers vector of perfect loops in thin foil $\mathrm{Ni}$ irradiated at $450^{\circ} \mathrm{C}$ within the damage profile: (a-e) TEM images of the Frank loop under different two-beam conditions with diffraction vector $\mathbf{g}$ indicated by red arrows with the same scale bar in (a); (f) Geometry of the crystal orientation, loop plane and loop Burgers vector to determine the loop nature using the inside-outside method [27].

The third zone $(2.0-2.5 \mu \mathrm{m})$ is outside the irradiated depth. This layer is dominated by dislocation lines and loops. It is interesting to note that no stacking fault contrast is detected in most loops in this zone as shown in Fig. 1(d) though some loops are too small $(<5 \mathrm{~nm})$ to confirm. Then, the type and nature of loops in the second damage zone is determined. Fig. 4(a-g) present a representative zone at about $2.2 \mu \mathrm{m}$ depth under different diffraction conditions. The diffraction vector $\mathbf{g}$ for each micrograph is indicated by the black arrow. Five typical loops (A, B, C, D and E) are chosen to show the determination of loop nature. For each $\mathbf{g}$, red circles point out the position of these loops. When a loop is invisible, the circle is dashed. A visibility table is made for used $\mathbf{g}$ and the Burgers vector for each loop is analyzed in Fig. 4(i) and they are all perfect loops. 

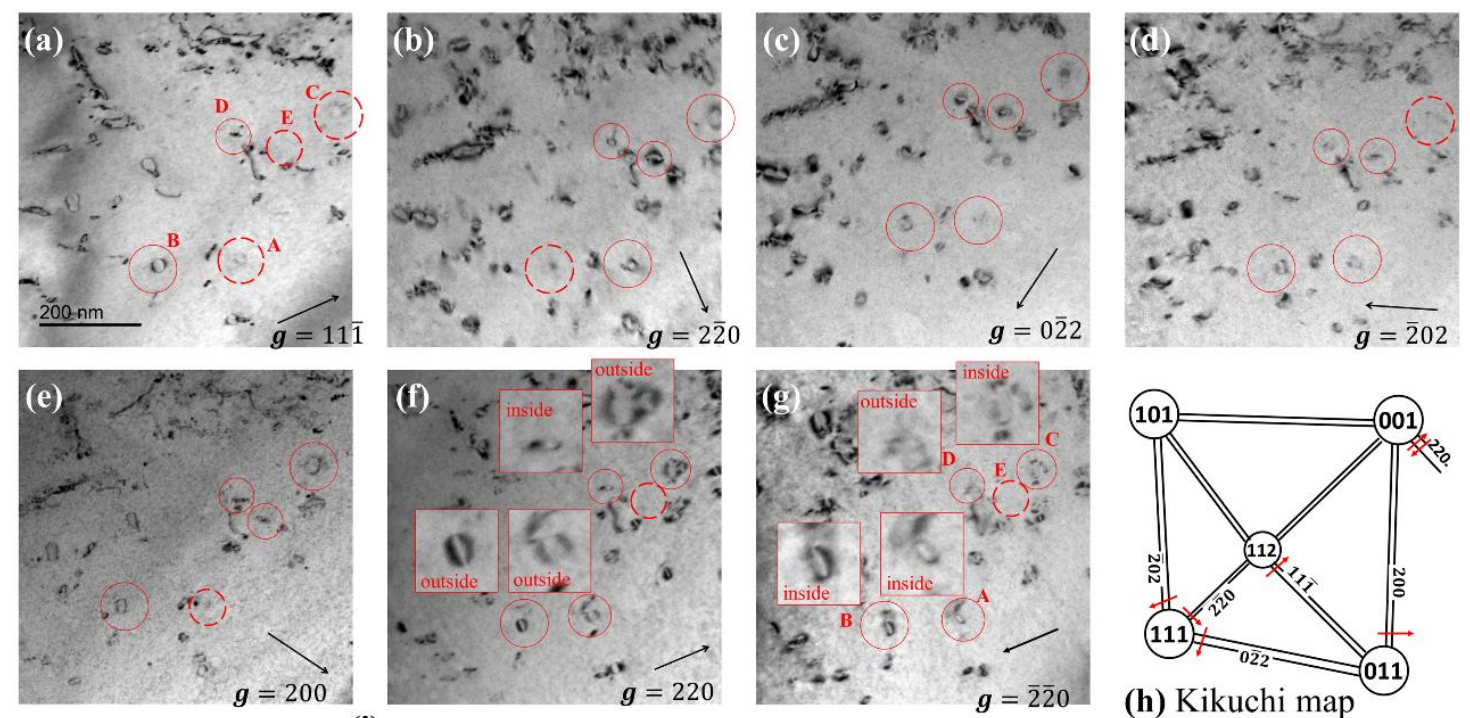

(h) Kikuchi map

\begin{tabular}{|c|c|c|c|c|c|c|c|c|c|}
\hline \multirow{8}{*}{ 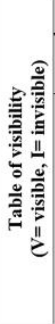 } & Zone axes & [112] & \multicolumn{3}{|c|}{ [111] } & [011] & \multicolumn{2}{|c|}{ [001] } & \multirow{2}{*}{ Loop } \\
\hline & Possible b $g$ & $11 \overline{1}$ & $2 \overline{2} 0$ & $0 \overline{2} 2$ & $\overline{2} 02$ & 200 & 220 & $\overline{2} \overline{2} 0$ & \\
\hline & $\pm \frac{1}{2}[110]$ & v & I & v & v & v & $\mathrm{v}$ & $\mathrm{v}$ & B \\
\hline & $\pm \frac{1}{2}[\overline{1} 10]$ & I & $\mathrm{v}$ & $\mathrm{v}$ & $\mathrm{v}$ & $\mathrm{v}$ & I & I & E \\
\hline & $\pm \frac{1}{2}[101]$ & I & $\mathrm{v}$ & $\mathrm{v}$ & I & $\mathrm{v}$ & v & $\mathrm{v}$ & C \\
\hline & $\pm \frac{1}{2}[10 \overline{1}]$ & $\mathrm{v}$ & $\mathrm{v}$ & $\mathrm{v}$ & $\mathrm{v}$ & $\mathrm{v}$ & $\mathrm{v}$ & $\mathrm{V}$ & D \\
\hline & $\pm \frac{1}{3}[011]$ & I & $\mathrm{v}$ & I & $\mathrm{v}$ & I & $\mathrm{v}$ & $\mathrm{v}$ & A \\
\hline & $\pm \frac{1}{3}[01 \overline{1}]$ & $\mathrm{v}$ & $\mathrm{v}$ & $\mathrm{v}$ & $\mathrm{v}$ & I & & $\mathrm{v}$ & \\
\hline
\end{tabular}

\begin{tabular}{|c|c|c|c|c|c|c|c|}
\hline \multirow{2}{*}{ Loops } & \multicolumn{4}{|c|}{ Contrast of loops along zone axis [001] } & \multirow{2}{*}{$\mathbf{g} \cdot \mathbf{b}$ for $\mathbf{g}$} & \multirow{2}{*}{ b } & \multirow{2}{*}{ Nature } \\
\hline & Safe? & b direction & $\mathbf{g}=[220]$ & $-\mathbf{g}=[\overline{2} \overline{2} 0]$ & & & \\
\hline A & safe & [011] & outside & inside & $>0$ & $1 / 2[011]$ & interstitial \\
\hline B & unsafe & [110] & I & 1 & I & 1 & 1 \\
\hline $\mathrm{C}$ & safe & [101] & outside & inside & $>0$ & $1 / 2[101]$ & interstitial \\
\hline $\mathrm{D}$ & safe & {$[10 \overline{1}]$} & inside & outside & $<0$ & $1 / 2[\overline{1} 01]$ & interstitial \\
\hline E & unsafe & {$[\overline{1} 10]$} & 1 & 1 & 1 & 1 & 1 \\
\hline
\end{tabular}

Fig. 4 Determination of the perfect loop nature out of the damage production zones in Ni irradiated $450^{\circ} \mathrm{C}$ to $2.3 \times 10^{15}$ ions. $\mathrm{cm}^{-2}$ : (a-h) Bright-field TEM images of irradiated Ni under ten two-beam conditions along different zone axis; diffraction vector $\mathbf{g}$ indicated by black arrow in each micrograph with the same scale bar for all images in (a); (i) table of visibility based on g.b value; (j) determination of loop nature based on inside-outside contrast in (f) and (g).

The inside-outside method with safe/unsafe condition is used to determine the nature of these perfect loops $[27,28]$. According to the method, the nature of a perfect loop can only be determined if the loop is under safe conditions. In the fcc structure, for a given observation zone axis, a perfect loop is under safe condition if the angle $\alpha$ between its Burgers vector $\mathbf{b}_{\mathbf{p}}$ and the zone axis $\mathbf{z}$ satisfies $\alpha<\left(90^{\circ}-35^{\circ}\right)=55^{\circ}$. In Fig. 4 , an inside-outside pair $( \pm \mathbf{g})$ is chosen along the zone axis [001] with $\mathbf{g}= \pm[220]$. The angle $\alpha$ for the Burgers vectors A, B, C, D, E (Fig. 4(i)) are respectively close to $45 / 90 / 45 / 45 / 90^{\circ}$ : loops A, C and D are under safe conditions. Fig. 4(j) presents the inside-outside analysis for loops under safe conditions (A, C and D). From their inside-outside behavior, loop A, C and D are interstitial-type. Other loops at depth $>2.0 \mu \mathrm{m}$ are analyzed and the same interstitial-nature is identified. Thus, we assume that the microstructure in 
1 this layer is dominated by interstitial-type perfect loops. The fourth zone (beyond the $2.5 \mu \mathrm{m}$

2 depth) is free of radiation-induced defects.

Based on these thorough and local analysis of dislocation loops, the global picture of

4 microstructure in $\mathrm{Ni}$ irradiated in the studied conditions is unambiguously revealed. The

5 microstructure appears to be dominated by vacancy-type Frank loops and perfect loops up to 1.3

$6 \mu \mathrm{m}$ depth, followed by a defect-free layer corresponding to the injection profile. Then, a layer

7 outside the damage profile is dominated by interstitial-type perfect loops. To our knowledge, a

8 drastic change of loop nature (vacancy-type v.s. interstitial-type) and loop type (both Frank and

9 perfect loops v.s. only perfect loops) along the depth direction is for the first time identified in

10 irradiated $\mathrm{Ni}$. It is critical to understand the origin of the change of loop nature and type.

11 In terms of loop nature, it is recognized that interstitial loops should grow under irradiation

12 while vacancy loops should rather shrink. All loops have indeed a positive bias with the

13 assumption that free migrating interstitials and vacancies are equally accessible to loops [30].

14 However, in this work, the vacancy loop dominated microstructure suggests strong excess of 15 vacancies/vacancy clusters (V-clusters) in irradiated zones (0 to $1.3 \mu \mathrm{m}$ depth in Fig. 1). A

16 plausible explanation of the vacancy excess is that interstitial clusters (I-clusters) are highly

17 mobile and can escape from the production zone, either to the surface or to unirradiated zones

18 while V-clusters are less mobile and remain within their production zone. This mechanism has

19 been studied by theoretical calculations $[9,20,21]$. Some I-clusters in the fcc structure were

20 suggested to be highly mobile and to migrate in long-range 1D motion while V-clusters have low

21 mobility [20,31,32]. In our previous work [19], the microstructure of irradiated thin foil Ni was

22 dominated by vacancy loops. Rate theory combined with an original production bias model was

23 suggested to explain the vacancy nature of loops. In the model, I-clusters formed within cascades

24 are assumed to be partially (about $10 \%$ for $260 \mathrm{~nm}$ thickness at $510^{\circ} \mathrm{C}$ [19]) absorbed by free

25 surfaces due to their high mobility, which can theoretically lead to the growth of vacancy loops.

26 The observation in this work (vacancy loops present up to $1.5 \mu \mathrm{m}$ in depth) demonstrates that the 
1 migration distance of I-clusters is much larger than the scale of thin foil thickness ( 200 nm). I-

2 clusters can migrate either to the surface or deeply in the material.

The stability of vacancy loops over SFT or voids may raise questions. In previous studies,

4 the relative stability of vacancy defects was investigated $[18,33]$. They revealed that in certain

5 cases, loops can indeed be the stable form. The average number of vacancies present in loops in

6 this study ( $\sim 20 \mathrm{~nm}$ in diameter giving $6.10^{3}$ vacancies $)$ is within the range of vacancy loop

7 domination [18]. Nevertheless, the variation of loop types observed in our sample (vacancy Frank

8 and perfect loops up to $1.5 \mu \mathrm{m}$ v.s. interstitial perfect loops above $2.0 \mu \mathrm{m}$ ) can be hardly explained

9 with only the 1D motion of I-clusters. Further mechanism should be involved to understand why

10 there are only perfect loops in unirradiated zones. A key factor is the difference among various

11 type of clusters. It is well known that, in fcc structure, I-clusters formed within the cascades are

12 in form of $\langle 100\rangle$ dumbbells, $\langle 110\rangle$ crowdions (perfect-loop-like clusters) or clusters with

13 stacking fault (Frank-loop-like clusters) [31,32,34,35]. They have different mobility: <110>

14 crowdions glide fast in 1D along their axis direction ( $<110\rangle$ directions) while $\langle 100\rangle$ dumbbells

15 display usually short-range 3D motion and defects with stacking fault are sessile. Moreover, it is

16 worth noting that interstitial $<100>$ dumbbells are reported to be unstable for $\mathrm{T}>426^{\circ} \mathrm{C}(700 \mathrm{~K})$

17 and to transform into interstitial <110> crowdions [35]. These subtle differences of cluster

18 mobility and stability give a natural explanation of both loop type and nature (interstitial-type

19 perfect loops) in unirradiated zones. <110> perfect-loop-like crowdions could be formed directly

20 within the cascades or from the transformation of $\langle 100\rangle$ dumbells, then they escape out of their

21 production zones, resulting in a vacancy excess in the irradiated zones and an interstitial-perfect-

22 loop dominated zone outside.

In our experiments, interstitial Frank loops are preferentially nucleated within large vacancy Frank loops as they provide a dilatation zone. Independent interstitial Frank loops are not detected outside vacancy loops. Indeed, newly nucleated Frank loops formed within cascades would shrink and disappear due to the excess of vacancies. 
The defect-free layer (1.3 to $2.0 \mu \mathrm{m}$ depth in Fig. 1) between the two loop-dominated zones

2 is also of great interest to study the injection peak. The injection profile is essential to reveal the 3 depth-dependency of radiation damage and calibrate damage calculation codes such as SRIM and

4 IRADINA. Generally, it is tricky to probe the implantation profile in self-ion irradiated materials.

5 Nevertheless, in this work, we can detect the damage peak using the defect-free layer. In fact, we

6 assumed that the injected interstitials compensate the interstitial loss due to 1D migration leading

7 to the defect-free layer. The injected atoms compensate partially the interstitial loss, inducing a

8 strong annihilation of vacancy loops in this zone. Hence, the injection peak prevents the growth

9 and gliding of vacancy $<110>$ crowdions and $1 / 2<110>$ loops. Therefore, the depth of the defect-

10 free layer should correspond to this peak. For the first time to our knowledge, these results allow

11 to experimentally identify the injection peak in self-ion irradiated specimens, providing precious experiment data to validate the calculation of radiation damage with dedicated codes (e.g., SRIM and IRADINA). The experimental validation of calculated implantation profiles is an important topic within the community as the phenomenal interpretation on radiation damage is closely related to them, e.g. in [36]. Furthermore the topic is particularly important for $\mathrm{Ni}$ as the calculated

16 profiles differ from SRIM and Iradina to the formerly used codes (TRIM98, Brice)[37]. The 17 observed defect free layer can not only be explained by an increase of defect recombination due to a higher damage rate at the damage peak $\left(2.7 \times 10^{-4} \mathrm{dpa} / \mathrm{s}\right)$. Indeed, past experiment realized with the same damage rate shows that vacancy loops grow at this level of flux [19]. Therefore,

20 the observed defect free layer is related to the implantation peak. Nevertheless, it observed here needs further understanding as the implanted ions at the injection peak, equal to $4 \times 10^{-4} \mathrm{appm}$ (Figure 1(e)), does not compensate for the predicted loss of interstitials, equal to $6 \times 10^{-3}$ appm (1.5 dpa $\mathrm{x} 4 \%$ displacement efficiency [38] x 10\% loss percent [19]), based on the actual knowledge of the material. The accuracy of the real defect production rate or/and the survival defect proportion in cascades is thus questioned. These parameters are critical to correctly predict and understand the properties of any material under any type of irradiation. 
Last, it is worth noting the high dislocation density at $\sim 2.1 \mu \mathrm{m}$ depth (Fig. 1(e)) outside the

2 damage profile. A plausible explanation is that the migration of clusters and loops (created in

3 irradiated zones) is enhanced by cascade damage [39]. Once they move into unirradiated zones,

4 their mobility reduces strongly so the majority remain at this depth leading to the loop 5 agglomeration.

In summary, fine microstructural analysis is performed in FIB-lifted Ni specimens irradiated by self-ion at $450^{\circ} \mathrm{C}$. The present findings lead to the following conclusions:

(1) For the first time, a drastic change of loop nature (vacancy-type v.s. interstitial-type) and

\section{Acknowledgments}

The research was supported by the Cross-cutting basic research Program of Division Energy of CEA (RTA Program), the RMATE project (CEA), the NEEDS program (CNRSCEA-EDFANDRA-AREVA-IRSN-BRGM) and by the French government, managed by the French 
1 0020). The support of JANNuS-Saclay-CEA team is acknowledged by authors for the ion

irradiation experiments. Also, the useful help of P. XIU and C. LU for the flash polishing is acknowledged.

\section{Reference}

[1] P. Yvon, Structural Materials for Generation IV Nuclear Reactors, 1st ed., Woodhead Publishing, United Kingdoms, 2016.

[2] S.J. Zinkle, G.S. Was, Acta Materialia 61 (2013) 735-758.

[3] D.B. Miracle, O.N. Senkov, Acta Materialia 122 (2017) 448-511.

[4] B. Gludovatz, A. Hohenwarter, D. Catoor, E.H. Chang, E.P. George, R.O. Ritchie, Science 345 (2014) 1153-1158.

[5] S.J. Zinkle, J.T. Busby, Materials Today 12 (2009) 12-19.

[6] X. Yan, Y. Zhang, Scripta Materialia 187 (2020) 188-193.

[7] S.I. Porollo, A.M. Dvoriashin, Yu.V. Konobeev, F.A. Garner, Journal of Nuclear Materials 442 (2013) S809-S812.

[8] T. Yoshiie, Q. Xu, Y. Satoh, H. Ohkubo, M. Kiritani, Journal of Nuclear Materials 283-287 (2000) 229-233.

[9] C. Lu, L. Niu, N. Chen, K. Jin, T. Yang, P. Xiu, Y. Zhang, F. Gao, H. Bei, S. Shi, M.-R. He, I.M. Robertson, W.J. Weber, L. Wang, Nature Communications 7 (2016) 13564.

[10] C. Lu, T. Yang, L. Niu, Q. Peng, K. Jin, M.L. Crespillo, G. Velisa, H. Xue, F. Zhang, P. Xiu, Journal of Nuclear Materials 509 (2018) 237-244.

[11] S.J. Zinkle, L.L. Snead, Journal of Nuclear Materials 225 (1995) 123-131.

[12] S. Kojima, T. Yoshiie, M. Kiritani, Journal of Nuclear Materials 155 (1988) 1249-1253.

[13] K. Urban, Physica Status Solidi (a) 4 (1971) 761-772.

[14] M. Kiritani, N. Yoshida, H. Takata, Y. Maehara, Journal of the Physical Society of Japan 38 (1975) 1677-1686.

[15] S. Ishino, Journal of Nuclear Materials 251 (1997) 225-236.

[16] K. Niwase, T. Ezawa, T. Tanabe, M. Kiritani, F.E. Fujita, Journal of Nuclear Materials 203 (1993) 56-66.

[17] T. Yoshiie, S. Kojima, Y. Satoh, K. Hamada, M. Kiritani, Journal of Nuclear Materials 191194 (1992) 1160-1165.

[18] K. Ma, B. Décamps, A. Fraczkiewicz, F. Prima, M. Loyer-Prost, Materials Research Letters 8 (2020) 201-207.

[19] K. Ma, B. Décamps, A. Fraczkiewicz, T. Jourdan, F. Prima, M. Loyer-Prost, Acta Materialia $212(2021) 116874$.

[20] H. Trinkaus, B.N. Singh, A.J.E. Foreman, Journal of Nuclear Materials 199 (1992) 1-5.

[21] C.H. Woo, B.N. Singh, Philosophical Magazine A 65 (1992) 889-912.

[22] R.E. Stoller, M.B. Toloczko, G.S. Was, A.G. Certain, S. Dwaraknath, F.A. Garner, Nuclear Instruments and Methods in Physics Research Section B: Beam Interactions with Materials and Atoms 310 (2013) 75-80.

[23] J.-P. Crocombette, C. Van Wambeke, EPJ Nuclear Sci. Technol. 5 (2019) 7.

[24] B. Horváth, R. Schäublin, Y. Dai, Nuclear Instruments and Methods in Physics Research Section B: Beam Interactions with Materials and Atoms 449 (2019) 29-34.

[25] A. Howie, M.J. Whelan, Proceedings of the Royal Society of London. Series A. Mathematical and Physical Sciences 267 (1962) 206-230.

[26] M.H. Loretto, R.E. Smallman, Defect Analysis in Electron Microscopy, Chapman and Hall, New York, 1975.

[27] M.L. Jenkins, Journal of Nuclear Materials 216 (1994) 124-156.

[28] D.M. Maher, M.H. Loretto, A.F. Bartlett, The Philosophical Magazine: A Journal of Theoretical Experimental and Applied Physics 24 (1971) 181-194. 
[29] Y. Liao, An Online Book (2006).

[30] R. Bullough, M.H. Wood, D.W. Wells, J.R. Willis, in: Dislocation Modelling of Physical Systems, Pergamon, 1981, pp. 116-141.

[31] D.J. Bacon, F. Gao, Yu.N. Osetsky, Journal of Nuclear Materials 276 (2000) 1-12.

[32] Y.N. Osetsky, D.J. Bacon, Modelling and Simulation in Materials Science and Engineering $11(2003) 427$.

[33] L.E. Seitzman, L.M. Wang, G.L. Kulcinski, R.A. Dodd, Journal of Nuclear Materials 141143 (1986) 738-742.

[34] Z. Yao, R. Schäublin, M. Victoria, Journal of Nuclear Materials 323 (2003) 388-393.

[35] Y.N. Osetsky, A.V. Barashev, Y. Zhang, Materialia 4 (2018) 139-146.

[36] C. Sun, F.A. Garner, L. Shao, X. Zhang, S.A. Maloy, Nuclear Instruments and Methods in Physics Research Section B: Beam Interactions with Materials and Atoms 409 (2017) 323327.

[37] F.A. Garner, J. Wang, L. Shao, S.A. Maloy, V.A. Pechenkin, Conference IWSMT-13 (2016) Chattanooga TN.

[38] G.S. Was, T. Allen, Journal of Nuclear Materials 205 (1993) 332-338.

[39] N. Khiara, F. Onimus, L. Dupuy, W. Kassem, J.-P. Crocombette, T. Pardoen, J.-P. Raskin, Y. Bréchet, Journal of Nuclear Materials 541 (2020) 152336. 